\title{
Poesía y pintura en la obra de Leopoldo Panero
}

\author{
José Enrique Martínez \\ Universidad de León
}

\section{RESUMEN}

Es bien conocida la labor de Leopoldo Panero en las Bienales Hispanoamericanas de Arte celebradas durante la década del 50; de ahí que este artículo se ocupe de un aspecto poco estudiado: los escritos en prosa y verso de Panero sobre pintura. En general se trata de textos breves en prosa y de escasos poemas, pero la pintura está muy presente en su obra como alusión o como comparación, con continuas correspondencias entre poesía y pintura. Más que la técnica y la forma, a Panero le interesó lo que en el arte hay de humanismo y de espiritualidad que trasciende la materia.

Palabras Clave: pintura, poesía, correspondencias, interpretación poética, Leopoldo Panero.

\section{Poetry and painting in the work of Leopoldo Panero}

\begin{abstract}
Leopold Panero's work is widely known in «Las Bienales Hispanoamericanas de Arte» celebrated during the 50's decade. However, this article studies a theme that has not received much attention: Panero's writings, prose and verse, on painting. Although they consist on brief narratives and a few poems, painting is deeply considered in his work as an allusion or comparison with continuous correspondences between poetry and painting. Panero was more interested in humanist and spiritual concepts that transcend the physical reality than in form or technique.
\end{abstract}

Key words: Painting, Poetry, Correspondences, Poetic interpretation, Leopoldo Panero.

«Leopoldo Panero fue un gran poeta de la pintura, del libro y de la vida», según expresó el pintor Benjamín Palencia. Y Pedro Mozos afirmaba lo mismo: «Era un gran poeta de la pintura a la que amaba profundamente» (Sánchez-Camargo, 1965: 190). La relación personal de Leopoldo Panero con la pintura y los pintores hay que situarla en el marco de las tres Bienales Hispanoamericanas de Arte, en las cuales el poeta ejerció de Secretario General. La primera Bienal se inauguró en Barcelona en octubre de 1951; la segunda, en la Habana de Fulgencio Batista en 1954; y la tercera, en Barcelona a finales de septiem- 
bre de 1955; cada una de ellas derivó en exposiciones y muestras en distintas ciudades españolas y americanas que trajeron a Leopoldo Panero muy ocupado durante esos años. De todo ello ha dado cuenta exhaustiva Miguel Cabañas Bravo en varias monografías, la última de las cuales en el tiempo es la titulada Exilio e interior en la bisagra del Siglo de Plata español, con un largo subtítulo: El poeta Leopoldo Panero y el pintor Vela Zanetti en el marco artístico de los años cincuenta (2007). Cabañas Bravo revisa las tres Bienales, atendiendo tanto a su concreto desarrollo como al contexto político y artístico-cultural que orientó su nacimiento y sus sucesivas ediciones a partir del inicio del decenio de los 50; da cuenta de las polémicas que suscitaron, de las reacciones en forma de «contrabienales», de la repercusión de las Bienales dentro y fuera de España, de los países participantes en cada edición y de las razones de su acabamiento, sustituidas las Bienales por las exposiciones de «Arte de América y España» en relación con nuevos intereses político-culturales que no es el momento de explicitar. En la monografía citada hallará el lector interesado los datos que atañen a la esforzada labor de Leopoldo Panero, «el alma de las Bienales Hispanoamericanas», como dijo de él el crítico de arte Manuel Sánchez-Camargo, quien ponderó el entusiasmo y el tesón con que llevó a cabo un trabajo «que suponía cambiar oficialmente el criterio estético del país» (Sánchez-Camargo, 1965: 187). Acaso haya que reparar en las relaciones que el poeta mantuvo con los pintores, amistándose con muchos de ellos, y singularmente con los de la España del destierro, fruto de las cuales fue, entre otros posibles, «el retorno definitivo del errante muralista que en tantas paredes del mundo había dejado su huella» (Cabañas Bravo, 2007: 25), Vela Zanetti, autor, entre otras obras, del mural finalmente titulado Derechos Humanos que se le encargó para la sede de las Naciones Unidas en Nueva York, como es bien sabido; en efecto, Vela Zanetti regresó a su patria a finales de marzo o primeros de abril de $1960 \mathrm{y}$, como varias veces se ha contado, en el aeropuerto le esperaba un amigo, Leopoldo Panero.

Para todos estos aspectos remito una vez más a la erudita monografía de Cabañas Bravo. Lo que yo deseo considerar es el hecho de que la mencionada relación con pintores, sin dejar a un lado el gusto personal del poeta astorgano por la contemplación fruitiva de sus lienzos, propició algunos escritos, singularmente algunos poemas, no muchos a decir verdad, que prolongan en el tiempo la relación secular entre pintura y poesía. De esta faceta es de la que quiero ocuparme, como complemento teórico-crítico al documentado e importante estudio de carácter histórico de Cabañas Bravo.

Como recuerda Huerta Calvo, ya en 1973 lamentaba Gerardo Diego - poeta que «llegó a escribir una importante obra ensayística sobre pintura y pintores» (Díez de Revenga, 1996: 7) — la escasez de escritos de Panero sobre arte, dada su vinculación con los artistas a través de las Bienales (Huerta Calvo, 2007: $\mathrm{XX}$ ). Se trata, además, de textos siempre breves, reseñísticos la mayor parte de las veces. Y en lo que se refiere a su obra lírica, los poemas de asunto artístico, concretamente pictórico, tampoco abundan. Sin embargo, la pintura está muy 
presente en la obra de Panero como referencia, alusión o comparación, estableciendo continuas correspondencias entre poesía y pintura.

Limitándonos al ámbito pictórico y, de momento, a sus escritos en prosa, lo que parece claro es que las Bienales Hispanoamericanas de Arte suscitaron un interés por el ámbito de la pintura que hasta entonces no se había manifestado en el poeta, al menos por escrito, pues los artículos de tal tenor aparecen publicados entre 1957 y 1961, a excepción del titulado «Salvador Dalí vuelve a la Costa Brava» (Panero, 2007: 491-492) ${ }^{1}$, indudablemente de 1948, fecha en que el pintor ampurdanés regresó a España, concretamente el 28 de julio de 1948, artículo, de todas formas, de escaso interés para el fin que perseguimos en este trabajo, y a excepción también de «El molino de Gregorio Prieto» (Panero, 2007: 493-494), publicado en un catálogo de $1950^{2}$ en el que Panero se hace eco de un deseo cumplido del autor: poseer un molino donde ubicar su estudio, algo acordado por el ayuntamiento de su pueblo, Valdepeñas (donde había nacido en 1879), que en 1950 dio su nombre a una calle y le regaló un molino «para que cuelgue allí sus pinturas y lo convierta en viviente museo de su obra»; la publicación del escrito de Panero coincide con la instalación definitiva del pintor en Madrid, de regreso de su casa londinense en el Hyde Park, donde acogió a Luis Cernuda y donde lo visitó Panero, ganándose su amistad, durante su estancia en Londres en los años 1946-1947 como Lector Bibliotecario del Instituto de España recién fundado en aquella capital.

Los escritos en prosa de Panero sobre pintores y lienzos no rayan a la altura de los poemas ecfrásticos, es decir, sobre obras pictóricas. En general son ocasionales y acaso de compromiso, redactados para presentar un catálogo o para reseñar algún libro relacionado con el arte. De un catálogo forma parte el texto titulado «La pintura de Cirilo Martínez Novillo» (Panero, 2007: $495)^{3}$, pintor y grabador nacido en Madrid en 1921, discípulo de Vázquez Díaz y perteneciente a la llamada escuela de Madrid, de la que formaban parte pintores que se vinculaban a un nuevo modo de sentir el paisaje; Panero celebra la evolución pictórica de Martínez Novillo hacia la «liberación de la materia» en pos de la «libertad expresiva que su nueva obra transparenta», obra en la que «la realidad se ennoblece; es decir, se espiritualiza», algo que nos parece acorde con la poética misma de Panero, que en el artículo titulado

${ }^{1}$ En todos los casos, la referencia (Panero, 2007), para los artículos en prosa, se citan por el volumen Panero, Leopoldo. Obra completa. Prosa, tal como consta en la bibliografía final. Anota el editor respecto al artículo sobre Dalí: «Texto mecanografiado en M [Málaga. Fondo manuscrito de L. Panero depositado en el Centro Cultural de la Generación del 27], que no sabemos si llegó a publicarse» (Huerta Calvo, 2007: 553, nota CLXXIV).

2 «En exposición Gregorio Prieto. Oleos, s.l., Dirección General de Propaganda, 1950, s.p. Este pequeño catálogo reúne textos de Eduardo Llosent, Marguerita Sarfatti, Zacarías Papantonio, y Jean Cassou» (Huerta Calvo, 2007: 553, nota CLXXV).

${ }_{3}$ «Presentación a un catálogo de C. Martínez Novillo». Madrid, Ediciones de la Dirección General de Bellas Artes, diciembre de 1958" (Huerta Calvo, 2007: 453, nota CLXXVI). 
«Vecindad con el alma» definió la poesía como «vecindad de la palabra con el alma» (Panero, 2007: 222). Entre los libros reseñados en Blanco y Negro figuran El Greco y Toledo (1956) de Gregorio Marañón (Panero, 2007: 479480), El tiempo en el arte (1958) de Camón Aznar (Panero, 2007: 481-482), Entendimiento del arte (1959) de Juan Antonio Gaya Nuño (Panero, 2007: 483-484) e Italia con Benjamín Palencia (1959) de Carmen Castro (Panero, 2007: 534-535), con dibujos del gran pintor albaceteño. En tales reseñas destaca Panero el humanismo de los autores y su calidad intelectual y humana; en la última caracteriza la pintura de uno de sus amigos admirados, Benjamín Palencia, valorando así el libro de Castro:

No sólo no(s) descubre una Italia prodigiosamente sentida y vivida por el más alto pintor de nuestros días, sino que nos ayuda a conocer más íntimamente su propia pintura y a comprenderla desde sus vivientes raíces, que están en Italia tanto como en Castilla, entrecruzando en una misma hermosura el más noble pasado y el presente más puro del arte español contemporáneo (Panero, 2007: 535).

Pero, sin duda, el texto paneriano sobre arte de mayor interés es el titulado «La rosa en la balanza. Un nombre para La Venus del espejo» (Panero, 2007: 489-490), publicado en el número de homenaje a Velázquez que le tributó la revista Mundo Hispánico en $1961^{4}$ con motivo de la exposición «Velázquez y lo velazqueño» en el Casón del Buen Retiro durante algunos meses de 1960-1961, exposición en la que se pudo contemplar «La Venus del espejo», traída de la National Gallery londinense, «donde tantas veces mis ojos se lo aprendieron de memoria», como escribe el poeta astorgano. El título del artículo de Panero alude al de un poemario del poeta argentino Leopoldo Marechal, que en 1944 publicó La rosa en la balanza (Marechal, 1944), un título «asombrosamente exacto, y, como tal, bellísimo», que a Panero le parece que sirve maravillosamente «para comprender desde dentro y apresar desde fuera, la esencia, o la calidad más alta del cuadro velazqueño». No otro nombre que «La rosa en la balanza» debe buscarse — piensa Panero- a la hermosa Venus velazqueña, llena de plenitud y equilibrio, en la que, a diferencia de sus bufones y retratos, «ni siquiera un pétalo de demasía inclina o vence el fiel de la balanza»; escribe Panero:

No es, pues, extraño, vano o accidental, este imaginario paralelismo, esta correspondencia, este súbito acercamiento entre las palabras lejanas de un lejano poeta argentino y la inmediata realidad o presencia entre nosotros de este humanísimo desnudo. La memoria del título y la contemplación de la pintura han casado de pronto, como si estuvieran hechos el uno para la otra, como si las errantes palabras vinieran en busca de su materia propia y se ajustaran a ella como la piel al cuerpo (Panero, 2007: 489).

\footnotetext{
${ }^{4}$ El homenaje a Velázquez corresponde al número 155 de Mundo Hispánico; el texto de Panero puede leerse en la p. 69 (Huerta Calvo, 2007: 552, nota CLXXIII).
} 
Pero Panero no se queda en la mera correspondencia entre palabra —el título de Marechal - e imagen, sino que expresa, desde la íntima fruición contemplativa, «lo que hay en esta Venus de verdaderamente intraducible y singular:

La sorprendente armonía, el maravilloso equilibrio, entre desnudez y desnudamiento, o entre pureza y sensualidad, que constituye, a mi juicio, el máximo encanto del cuadro de Velázquez y su intransferible secreto: el secreto vital, y no artístico simplemente, que es ley de su pintura, y que está siempre en su mano cuando pinta (lo bello igual que lo deforme), ennobleciendo cada una de sus obras. La belleza está ahí, pero no es sólo belleza: es vida. Lo corpóreo parece el alma misma. La piel tiene intimidad: eso es lo prodigioso. La generosidad vital de Velázquez todo lo salva, como si redimiera nuestros ojos (Panero, 2007: 490).

Una vez más, Panero, más allá de la técnica, más allá de la forma, pondera lo que en la obra de arte, pintura, música o poesía, hay de humanismo, de vitalidad, de espiritualidad que trasciende la materialidad de la obra artística, idea recurrente a lo largo de la obra en prosa de Panero y que podemos observar, como es lógico, en las correspondencias que establece entre poesía y pintura, un aspecto extraordinariamente interesante, por cuanto la pintura le sirve de comparación para caracterizar la poesía.

Como se sabe, Horacio estableció el símil en su Epístola a los Pisones, que reducido al ut pictura poesis («la poesía como la pintura»), fue abusivamente utilizado después; pero en realidad, Horacio habla únicamente de la poesía, y la comparación no busca más que un mejor entendimiento de la misma en relación con los efectos que provoca:

La poesía es como la pintura; habrá una que te cautivará más si te mantienes cerca, otra si te apartas algo lejos; ésta ama la penumbra; aquélla, que no teme la penetrante mirada del que la juzga, quiere ser vista a plena luz; ésta agradó una sola vez; aquélla, aunque se vuelva a ella diez veces, agradará (otras tantas) (Horacio, 1987: 141).

Como señala Manuel Asensi, «lo que el De Arte Poética sugiere con la comparación entre la poesía y la pintura es que tomando en consideración el efecto (ethos) que la obra poética causa en el lector, espectador o crítico, no todas las poesías son iguales» (Asensi, 1998: 141). La tradición, en cambio, interpretó interesadamente que la poesía y la pintura eran artes miméticas idénticas y con idénticos fines. En todo caso, el tópico del ut pictura poesis resuena en los escritos panerianos sobre poesía. La comparación de un poeta con un pintor o de una obra poética con otra pictórica le sirve a Panero, como ya indicamos, para caracterizar al poeta o a su poesía, para entender mejor la poesía, para iluminarla por la semejanza o por el contraste.

Desde mi punto de vista el texto de Panero que expresa más dignamente su concepción de la poesía es el titulado «El sentido moral de la poesía española» (Panero, 2007: 16-36) que —según nota de Huerta Calvo (2007: 551, nota IV) - procede de una charla pronunciada en Valencia en 1953 y en los cursos universitarios de León en agosto de 1962, pocos días antes de su muer- 
te. Panero plantea la existencia de dos líneas poéticas en nuestra tradición, una vital, humanizadora, comunicativa, cuyos ejemplos representativos podrían ser Jorge Manrique y, más acá en el tiempo, Bécquer, Unamuno y Machado, y otra formalista, impersonal y elitista, con Góngora a la cabeza y el fervor gongorino suscitado con motivo del tercer centenario de su muerte en 1927, más la poesía pura y el arte por el arte. Quien haya leído a Panero entenderá fácilmente su defensa de lo que para él es la verdadera poesía: no la que presta culto a la palabra, sino la poesía de contenido humano y con trasfondo moral, reflejo del alma del creador y «expresión íntegra del hombre»: «las palabras lo son de verdad - escribe Panero- en tanto aciertan a revelarnos y transmitirnos la fuerza misma de la vida», en tanto vienen cargadas de humanidad. La referencia pictórica le sirve al poeta para dar plasticidad y relieve a sus ideas sobre la poesía:

Ciertamente la poesía se hace con palabras, pero con palabras encadenadas por el corazón. Como se hace con colores la pintura, pero con colores capaces de expresar, con frase de Vicente van Gogh tomada de una de sus cartas, los terribles sufrimientos humanos.

Lo que dignifica a la poesía, a la pintura, y a todas las creaciones artísticas del hombre es, justamente, su contenido humano, su vivencia moral, y no la maestría, el acabado, la externa perfección de la materia empleada en la obra (Panero, 2007: 17).

Interpretando a Panero, el material de uso puede ser distinto (palabra, sonidos, piedra, barro o colores) pero la finalidad artística es la misma: ser expresión de la vida y del alma humana. Escribe Panero, poniendo de relieve el fondo de humanidad que late en la pintura velazqueña y en las Coplas de Jorge Manrique:

En sus momentos más altos, en sus puntos de culminación, la poesía española ha sido siempre así; y no sólo la poesía sino todo el arte. La pintura de Velázquez, por ejemplo, la pintura de los enanos y bufones, de los tontos de Vallecas, de los infrahombres sociales, es esencialmente una pintura caritativa y de la más limpia hondura moral. No hay más que mirarla a los ojos.

[...] Lo que Velázquez parece decirnos es que también aquellos pobres seres deformes son hombres como nosotros: y su pincel, transido de piedad y de respeto, nos muestra persuasivamente a las humildes criaturas para hacernos sentir que somos sus hermanos, y que, don Diego de Velázquez, caballero de Santiago, pintor de cámara de su majestad católica, no sólo no desdeña pintar aquellos mínimos habitantes del real alcázar, sino que pone en ellos toda su simpatía y su ternura y los reconoce y acepta en su corazón.

En las elegíacas coplas manriqueñas la ejemplaridad es de signo opuesto y de excelso perfil, pero un mismo sentimiento radical late en el fondo de ambas creaciones y humanizaciones poéticas (Panero, 2007: 31).

No es mi deseo agotar todas las correspondencias de visión del mundo que Panero establece entre determinados poetas y distintos pintores. Pero hemos aludido a Velázquez y su visión piadosa y humanizadora de las criaturas humanas; en contraste sitúa Panero la actitud de Cela en sus Historias de España. Los cie- 
gos. Los tontos (Cela, 1957), propia, como dijo en su día Valle-Inclán, de quien mira a esos personajes desde arriba, moviendo los hilos de las marionetas:

Faltan en los retratos de tontos y ciegos que Cela nos ofrece en su alucinante galería [...] la piedad o la ternura que Velázquez puso en su pincel, al enfrentarse desde su realismo [...] con el mismo tema. Pienso por eso que en el caso de Camilo José Cela los ciegos y los tontos [...] son motivo o pretexto de su afilada narración más que raíz o tema de ella (Panero, 2007: 367-368).

En un largo estudio sobre «Jorge Guillén y Cántico» (Panero, 2007: 158$171)^{5}$ señala Panero que nadie después de Góngora ha creado «un lenguaje poético tan diamantino, tan implacablemente artístico, tan apuradamente bello y exacto» como el Guillén de Cántico, «que inventó una luz propia para sus palabras, como Beruete, un poco antes y dentro de la técnica pictórica impresionista, había encontrado una luz propia y única, fundente y esencial, para sus cuadros, para sus áridos paisajes y cenitales suburbanos del campo y cielo de Madrid» (Machado, 2007: 169). Aureliano de Beruete (1845-1912) cultivó, en efecto, los paisajes de modo impresionista y en ellos destaca la fina captación de la luz. Pero lo que nos importa es la facilidad con que acuden a la memoria de Panero pinturas y lienzos para dar cobertura plástica a su entendimiento de la poesía o de una determinada poesía. He aquí un perfecto ejercicio de correspondencia entre poesía y pintura en un artículo-reseña titulado «Aquel día en Jerusalén» (Panero, 2007: 134-135) ${ }^{6}$ :

Como pudiéramos hablar, traslaticiamente, del delicado y luminoso impresionismo de Juan Ramón Jiménez, por ejemplo (en esta línea Rueda sería el equivalente literario de Sorolla), cabría también hablar del violento expresionismo poético [...] de Dámaso Alonso.

Jugando a las correspondencias entre pintura y poesía, quizá nos fuese permitido situarlo, tomando pie en algunos de sus más recios y punzantes poemas de Hijos de la ira, al lado de José Gutiérrez Solana, el genial pintor de la fealdad, de la podredumbre y de la náusea (Panero, 2007: 134).

No es extraño, vista la familiaridad con la pintura que muestra Panero, que algunos poemas broten de la visión o la memoria de un lienzo como expresión del gozo o de la emoción de su contemplación.

Quiero indicar antes de nada que la relación entre poesía y pintura en este aspecto de la poetización de un cuadro (porque hay otras posibles relaciones, como la colaboración entre poeta y pintor, por ejemplo), la relación, digo, en cuanto verbalización, temporalización o sucesividad de un arte espacial como es una pintura determinada, es un asunto secular que en el siglo XX tuvo manifestaciones espléndidas, bien en poemas concretos, como «Retrato de

\footnotetext{
${ }^{5}$ El texto corresponde a una conferencia pronunciada en La Coruña en el verano de 1951 (Huerta Calvo, 2007: 551, nota LXII).

${ }^{6}$ «Aquel día en Jerusalén» fue publicado en Blanco y Negro, 2364, 24-VIII-1957 (Huerta Calvo, 2007: nota XXXIII).
} 
poeta (Fray H. Félix Paravicino, por el Greco)»(Con las horas contadas, 1958) y «Ninfa y pastor, por Tiziano» (Desolación de la Quimera, 1962) de Cernuda, o «La lágrima de San Pedro de "El Greco"» y «En la pintura de «El Bosco»», de Diego Jesús Jiménez (Fiesta en la oscuridad, 1976), bien en libros enteros de asunto pictórico, como los ya clásicos de Manuel Machado (Museo y Apolo), Unamuno (El Cristo de Velázquez) y Rafael Alberti (A la pintura), hasta llegar a tiempos recientes con poemarios como Exposición (1990) de Olvido García Valdés, El final de la contemplación (1992) de Luis Javier Moreno o Colección privada (2003) del colombiano Ramón Cote Baraibar, títulos en sí mismo muy significativos.

Panero, que mostró un aprecio inequívoco y permanente por Unamuno, uno de sus maestros reconocidos, junto a Antonio Machado y los románticos Wortsworth y Keats, consideró que el largo poema unamuniano El Cristo de Velázquez era uno de los «más iluminadores, hondos y espirituales de nuestra lengua», añadiendo que hasta un poeta de tan entrañada espiritualidad «necesitó para cantar el drama del Calvario centrar su poesía en una figuración corpórea, y personalizar, por así decirlo, su palabra en el Cristo pintado por Velázquez» (Panero, 2007: 39). A la espiritualidad desde la materia, diríamos resumiendo el pensamiento de Panero, o mejor, a la poesía desde la pintura, como hizo el astorgano en los poemas que citaré después.

Los poemas de Leopoldo Panero relacionados con la pintura, más allá de dedicatorias amistosas o alusiones ocasionales, no llegan a una decena ${ }^{7}$ : la epístola «A Daniel Vázquez Díaz», que según anotación de Javier Huerta fue «publicado en Exposición Homenaje a Vázquez Díaz, en 1953»"; el poema «Al maestro Vázquez Díaz en sus ochenta años», se publicó en otro Homenaje al pintor, con el motivo que indica el título del poema en $1962^{9}$; «Aldeana de Extremadura (pintada por Ortega Muñoz)», aparece dentro de Romances y canciones, publicados en $1960^{10}$, donde se encuadra también «Comarca», dedicado a Vela Zanetti, sobre un cuadro del pintor, según el parecer de Huerta Calvo (2007: I, CXXIII); «Pañuelo de agonía (Rouault)», dentro de [Poemas sueltos, 2] (Panero, 2007: II, 447-557), fechados entre 1950-1962, colección en la que aparece también el soneto «Homenaje a Valdés Leal»; y entre los Poemas inéditos (Panero, 2007: II, 559-665), los titulados «En presencia del alma (Los tontos)», referente a tipos de la pintura velazqueña, «Visión nocturna de Quesada», sobre un cuadro de Rafael Zabaleta, y «Cañadas», que, dedicado a Benjamín Palencia, recrea, según creo, motivos de la pintura del manchego.

\footnotetext{
${ }^{7}$ En todos los casos, la referencia (Panero, 2007: I; Panero:2007: II) envía a sendos volúmenes de poesía en Panero, Leopoldo. Obra completa. Poesía I. Poesía II, tal como consta en la bibliografía final.

${ }^{8}$ Exposición Homenaje a Vázquez Díaz, Madrid, Dirección General de Bellas Artes, 1953, pp. 71-72 (Huerta Calvo, 2007: II, 828, nota XVII).

${ }^{9}$ Homenaje a los ochenta años del pintor Daniel Vázquez Díaz, Madrid, Quixote Servicio de Arte Español, 1962, p. 49 (Huerta Calvo, 2007: II, 836, nota LIII).

${ }^{10}$ Romances y canciones. Cuadernos Hispanoamericanos, 121, 1960, pp. 17-34.
} 
Desde el punto de vista que he elegido me interesan no tanto los homenajes y recreaciones de un mundo pictórico como la poetización de un lienzo concreto, y singularmente los poemas referentes a sendos cuadros de Velázquez, Rouault y Ortega Muñoz, es decir, los poemas de carácter ecfrástico sobre un cuadro con figura humana representada.

Trascribo los poemas:

\section{ALDEANA DE EXTREMADURA (PINTADA POR ORTEGA MUÑOZ)}

Su intimidad da rostro al alma, y en la apretada mies del pecho la cabeza doblada rinde como si rezara en silencio.

¿Vuelve, besada, de la tarde? ¿Termina de cantar, y el eco de su apagada lejanía es el que oímos en el lienzo?

¡Cántaro lleno de aguas claras -Guadalupe, Asunción, Remedios-, que torna a pie desde la fuente cuando huele a luna el sendero!

Sombra, caricia del espíritu; volumen, placidez, sosiego. ¡Cántaro rico de olivares, puesta la mirada en el suelo!

¡Barro tocado de inocencia bajo el ocre corpiño negro que oprime en blancura profunda y en tibia castidad sus senos! (Panero, 2007: II, 431)

\section{PAÑUELO DE AGONÍA (ROUAULT)}

...En el delgado lienzo yace tu faz impresa, y en el límite tibio del amor que te ayuda tu soplo está, y la gruesa pincelada no es gruesa; y la mirada sabe: no vacila ni duda.

Sabemos de repente que el ala que te besa toma como un pañuelo tu misma piel desnuda, y que corre tu sangre sobre la tela ilesa, y que sufres de nuevo bajo la imagen ruda. 
¡Claridad insondable que en todo ser callado - pintor mudo y minado por la palabra viva hace de lo invisible color que nadie ha hallado!

¡Fresco, tierno, rasgado, libre de abajo a arriba, así a mi pecho oscuro tu rostro está pegado! ¡Gracias por tu presencia, de un pañuelo cautiva! (Panero, 2007: II, 537)

\section{LA PRESENCIA DEL ALMA (LOS TONTOS)}

No hay cosa más desnuda en este mundo que su presencia: nada comparable al fulgor celeste de esa luz última y hablada.

¡Nadie, nadie, que te conteste a tu pregunta más callada como esa sombra de aérea veste que el cielo rasga al ser mirada!

La llaman alma... ¡Cuerpo, escoria torpe y salvada: rosas secas, gracia helada, tonto de Coria!

¡La llaman fiebre, señas, muecas, rostros de Dios en la memoria, bulto de un niño de Vallecas! (Panero, 2007: II, 590)

Fijémonos inicialmente en los títulos: «Aldeana de Extremadura (Pintada por Ortega Muñoz)», «Pañuelo de agonía (Rouault)» y «En presencia del alma (Los tontos)». Cada título, como vemos, dispone de un subtítulo aclarador que alude al hecho de que se trata de pinturas, de cuadros, porque Panero ha dado un título inicial que tal vez por sí solo no nos especifique, de inicio, que nos hallamos ante la verbalización de un cuadro pictórico. De ahí que los paréntesis acojan el nombre del pintor, un nombre propio que, por lo tanto, designa e identifica un pintor concreto «en el universo de preocupaciones y saberes comunes al hablante y al oyente» (Alarcos Llorach, 1994: 68), al poeta y al lector. El título sirve, por lo tanto, para ponernos en situación. "Pañuelo de agonía», en ese universo de saberes comunes, traduce líricamente el título original del cuadro de Rouault, «La Sainte Face» (1946) («La Santa Faz»), dándole un sentido de doloroso dramatismo, mientras que «En presencia del alma» quiere trascender la mera figuración corpórea de «Los tontos» pintados por Velázquez.

El título ejerce funciones fáticas o de contacto, en tanto que abre el canal de comunicación, y pragmático-informativas en su relación dialéctica con el texto, anticipando «notas de referencialidad del universo imaginario», convirtiéndose así en «vector que orienta el proceso de descodificación por parte del lec- 
tor» (López-Casanova, 1994: 13). El título ecfrástico tiene, además, especial potencia informativa, pues da noticia del texto que anuncia y, a la vez, del cuadro al que remite. Más aún, el título ecfrástico reenvía a un contexto histórico, cultural, artístico, etc., y a su posible proyección sobre el texto que introduce: el título «En presencia del alma (Los tontos)» trae a la memoria la corte de los Austrias y su séquito de bufones, enanos y seres objeto de mofa y diversión; y nos introduce en el universo pictórico de Velázquez, que esforzó sus pinceles para, sin menguar sus deformidades, dotarlos de humanidad, de alma, como canta Panero en su soneto; y acaso, para un entendido en arte, le recuerde a los seres deformes pintados, antes de Velázquez, por Sánchez-Coello, Pantoja y Villandrando, y después de Velázquez, por Carreño y Herrera el Mozo. En suma, el título ecfrástico agrega a la función catafórica propia de todo título, una función anafórica que alude al carácter intertextual del poema, mirando hacia atrás (el cuadro) y hacia adelante (el texto), como un dios jánico.

He reiterado varias veces el adjetivo «ecfrástico» referido al título y extensible al poema correspondiente. La écfrasis es una figura retórica descriptiva que significa «evidenciar», «mostrar o poner ante los ojos» del lector el objeto descrito o, como dice Fernando de Herrera, «cuando lo que se trata se representa con palabras de modo que parezca que se ve con los ojos»(Gallego Morell, 1972: 326); describir, evidenciar el objeto ausente, el cuadro pictórico, es el sentido con que se usa «écfrasis» en la actualidad. Poner ante los ojos el cuadro ausente significa evocarlo mediante la descripción. La descripción pretende suplir la ausencia del objeto poetizado. Reiterar o evocar en el título del poema el título de un cuadro debería evitar la écfrasis esforzada por mostrar aquel ante los ojos de la memoria o de la imaginación del lector, pero no es así, pues el poeta, como indiqué, quiere llenar el hueco de la ausencia describiendo el objeto, el cuadro evocado. Podría hacerse por medio de la reproducción del cuadro, como fue el caso de Manuel Machado en la primera edición de Apolo (1911), ilustrado con las láminas de los lienzos que inspiraron los poemas correspondientes; pero tales ilustraciones desaparecieron en ediciones posteriores. La écfrasis ha dado lugar a estudios teóricos de gran altura conceptual en relación con la mímesis que implica, pues al fin y al cabo el poema ecfrástico es representación de una representación: el objeto-la aldeana de Extremadura o los tontos de Velázquez - siempre queda más allá del cuadro, siempre imposible de apresar por la pintura o por las palabras; la ausencia es doble en el poema: el objeto representado en el cuadro y el cuadro mismo. De ahí el componente elegíaco del poema ecfrástico, incapaz de evitar la pérdida del objeto (Monegal, 1998: 39-57).

Pero los poemas de Panero son muy parcos en elementos descriptivos: en el poema «En presencia del alma» sólo los nombres «tonto de Coria» $\mathrm{y}$ «niño de Vallecas» identifican a «los tontos» a los que se refiere el poema; «Pañuelo de agua» ofrece sintagmas descriptivos como «delgado lienzo», «faz impresa», «gruesa pincelada»; y «Aldeana de Extremadura» presenta rasgos descrip- 
tivos de la figura, mínimos, pero que permiten evidenciarla: «cabeza doblada», «cántaro lleno de aguas claras», «mirada en el suelo», «ocre corpiño negro». De ahí que pensemos que Panero lo que nos da en sus poemas es la verbalización, más que de un cuadro, de una emoción suscitada por la contemplación o, en otro extremo, una interpretación que podemos llamar poética. Y es que, como dice Riffaterre, la écfrasis tiende a sustituir el análisis de una pintura por el relato de lo que antecede o sigue al acontecimiento o a la situación en ella representados. Y este relato superador de la figuración pictórica es, en el caso de Panero, anímico, sentimental, interior, espiritual en suma. Al fin y al cabo, el poeta proyecta sobre los cuadros su estado de ánimo, su deseo personal, su pensamiento trascendente. Es lógico, puesto que dentro del carácter selectivo que tiene toda écfrasis, el poeta ha elegido unos pintores y unos cuadros determinados que pasan a formar parte de su museo particular, de su «colección privada». De ahí el carácter de encomio y homenaje que significa la écfrasis, la elección, que suele llevar aparejada cierta identificación artística, emocional o de otro tipo. Pensemos, por ejemplo, en el soneto eneasílabo en torno a «Los tontos» de Velázquez. Antes cité un fragmento en prosa, de 1953 al menos, quizás anterior al soneto. Allí Panero, recordemos, declaraba que «la pintura de Velázquez [...], la pintura de los enanos y bufones, de los tontos de Vallecas, de los infrahombres sociales, es esencialmente una pintura caritativa y de la más limpia hondura moral»; hablaba Panero de «la chispa de humanidad de sus pupilas», las de los bufones, de que Velázquez hace ver «que también aquellos pobres seres deformes son hombres como nosotros», nos recordaba el pincel del pintor «transido de piedad y de respeto» hasta «hacernos sentir que somos sus hermanos» (hermanos de los seres deformes), y que Velázquez pone en tales seres «toda su simpatía y su ternura y los reconoce y acepta en su corazón» (Panero, 2007: 31). En el hermoso párrafo de Panero hay una identificación sentimental plena con el mundo espiritual de Velázquez, con la generosidad y la piedad que exhala la pintura de los enanos y bufones de la corte, sencillamente porque también Panero extiende la misma mirada piadosa sobre el mundo, trascendiendo las apariencias, tal como observamos en el soneto, que viene a decirnos que por encima o por debajo de las deformidades, el tonto de Coria y el enano de Vallecas son seres con «alma».

El pintor Rouault, Georges Rouault (1871-1958) debió interesarle a Panero por el vigor un tanto rudo — sus motivaciones eran más religiosas y solidarias que pictóricas y estéticas - con el que pinta rostros de Cristo y figuras bíblicas; Javier Huerta (2007: 599, nota 298) señala que el último modo de Panero se identifica con la imaginería religiosa de Rouault, al que también alude en otro poema, el titulado «La poesía» («y callamos, como una quemadura, / como una corteza arrancada que muestra dentro / su rostro de Rouault en leño vivo»). Y entre los rostros pintados por el francés quizá ninguno le impresionó tanto a Leopoldo Panero como «La Sainte Face», que lleva fecha 
de 1946 y que aparece con una gran fuerza pictórica en el contraste entre el negro y el color y en la intensidad de sus ojos negros, a cuya mirada fija y resolutiva alude Panero: «Y la mirada sabe: no vacila ni duda», añadiendo notas referentes al sufrimiento que expresa, a la capacidad de la poesía y de la pintura para dar forma a lo invisible, y al entrañamiento religioso por medio de un símil («así a mi pecho oscuro tu rostro está pegado»). Es a ese rostro al que dirige sus palabras el sujeto, el yo del poema, creando de este modo un efecto de intimidad, de cercanía sentimental, casi de plegaria a una imagen sacra, pues las palabras de este soneto en alejandrinos, más que a Dios o Cristo, se dirigen a su imagen, a su faz «de un pañuelo cautiva» como dice el verso último, que reitera semánticamente el primero, «En el delgado lienzo yace tu faz impresa»; más allá de la representación, «lo invisible», Cristo. Sutilmente, Panero ha ofrecido su interpretación estética de la pintura por medio de una antítesis: «la gruesa pincelada que no es gruesa»; el trazo es grueso, en efecto, y la atmósfera que exhala el lienzo es tensa, pero Panero sugiere de forma aguda el efecto de dolor, de aflicción silenciosa que brota de la pintura y que tal vez roza lo delicado («el ala que te besa», «tu misma piel desnuda») y, desde luego, la profundidad interior, como expresa el verso octavo: «y que sufres de nuevo bajo la imagen ruda».

No puedo menos que estar de acuerdo con Riffaterre cuando señala que la écfrasis descifra antes al contemplador, al poeta, que al cuadro o la escultura (Riffaterre, 2000: 174), algo también palpable cuando reparamos en «Aldeana de Extremadura (pintada por Ortega Muñoz)», cuadro que consiguió el Gran Premio de Pintura en la II Bienal Hispanoamericana de Arte. Godofredo Ortega Muñoz pintó principalmente paisajes, bodegones y tipos de su tierra como esta «Aldeana de Extremadura»; caracteriza a sus pinturas la sobriedad cromática y el efecto emotivo. Y es emoción y pensamiento lo que emerge de la contemplación paneriana. De ahí las interrogaciones de la segunda estrofa - el poema es un romance de versos eneasílabos distribuidos en cuartetas- marcadamente enfáticas, que no piden respuesta ni información alguna; son simplemente manifestaciones externas de la meditación que el cuadro motiva en el poeta. Todo el poema tiene ese signo de contemplación sosegada y de interpretación poética del cuadro, una interpretación que no es técnica ni académica, ni requiere el análisis previo. Es una derivación metafórica, una atribución de significado. La interpretación poética es fiel a la «revelación» que tiene o tuvo lugar durante la contemplación, en un intento de captar el secreto que el lienzo vela: el momento de fulgor interior o de alumbramiento de la mirada que tuvo lugar y cuya llama el poeta quiere alimentar con el fin de transmitir su luz a los lectores. Por así decir, Panero no sólo ve el cuadro, también lo escucha («¿...el eco de su apagada lejanía / es el que oímos en el lienzo?») y lo que el cuadro le dice es el poema. Por cierto que esta espléndida composición rezuma cierta sensibilidad azoriniana. No es extraño, si atendemos a las palabras que Panero puso al frente de las Epístolas 
para mis amigos y enemigos mejores (1952-1953) (Panero, 2007: I, 283-323), que hablan de la pasión con que leyó al maestro de Monóvar en su juventud: «Sin Azorín yo sería, fundamentalmente, otro del que soy ¡Dios mío, cuánto le debo! [...] Sin Azorín, mi poesía entera quedaría borrada» (Panero, 2007: I, 285); pero el análisis de la afinidad con Azorín, patente, por ejemplo, en la tercera estrofa, nos llevaría por otro camino que no nos toca explorar. En este artículo se trata, más bien, de suscitar el interés por esta parcela lírica de quien fue considerado «gran poeta de la pintura».

\section{BIBLIOGRAFÍA CITADA}

Alarcos Llorach, Emilio (1994). Gramática de la Legua Española. Madrid: Espasa-Calpe. Asensi, Manuel (1998). Historia de la teoría de la literatura (desde los inicios hasta el siglo XIX). Vol. I. Valencia: Tirant lo Blanch.

Cabañas Bravo, Miguel (2007). Exilio e interior en la bisagra del Siglo de Plata español. El poeta Leopoldo Panero y el pintor Vela Zanetti en el marco artístico de los años cincuenta. León: Ayuntamiento de Astorga.

Cela, Camilo José (1957). Historias de España. Los ciegos. Los tontos. (Portada e ilustraciones de Manuel Mampaso). Madrid: Arión.

Díez de Revenga, Francisco Javier (1996). «Gerardo Diego, la pintura, los pintores y dos textos inéditos». Turia. 35-36, pp. 7- 21.

Gallego Morell, Antonio (1972). Garcilaso de la Vega y sus comentaristas (ed.). Madrid: Gredos.

Herrera, Fernando de (1580). Obras de Garcilaso de la Vega con Anotaciones de..., en Antonio Gallego Morell (ed.) (1972), Garcilaso de la Vega y sus comentaristas. Madrid: Gredos, pp. 305-594.

Horacio (1987). Epístola a los pisones, en Aristóteles, Horacio, Artes poéticas (Ed. bilingüe, trad. de Aníbal González). Madrid: Taurus, pp.127-160.

Huerta Calvo, Javier (2007). «Estudio preliminar» y «Aparato crítico», en Leopoldo Panero, Obra completa. Prosa. León: Ayuntamiento de Astorga. 3 vols., pp. XIII-XL y 551-554.

López-Casaova, Arcadio (1994). El texto poético. Teoría y metodología. Salamanca: Colegio de España.

Marechal, Leopoldo (1944). La rosa en la balanza (Odas para el hombre y la mujer y Laberinto de amor). Buenos Aires: Editorial Sudamericana.

Monegal, Antonio (1998). En los límites de la diferencia. Poesía e imagen en las vanguardias hispánicas. Madrid: Tecnos.

Panero, Leopoldo (2007). Obra completa. Poesía I. Poesía II. Prosa. (Ed. crítica de Javier Huerta Calvo). León: Ayuntamiento de Astorga. (3 vols.).

Riffaterre, Michel (2000). «La ilusión de la écfrasis», en Antonio Monegal (ed.). Literatura y pintura. Madrid: Arco-Libros, pp. 161-183.

Sánchez-Camargo, Manuel (1965). «Leopoldo Panero y la pintura española contemporánea», Cuadernos Hispanoamericanos, 187-188, pp. 186-191.

Fecha de recepción: 11 de febrero de 2010

Fecha de aceptación: 15 de octubre de 2010 